\title{
Protein disulphide isomerase-induced refolding of sonochemically prepared Ribonuclease A microspheres
}

\author{
Margarida M. Fernandes ${ }^{\mathrm{a}, 1}$, Raquel Silva ${ }^{\mathrm{a}, 1}$, Helena Ferreira ${ }^{\mathrm{a}, \mathrm{b}}$, Ilaria Donelli ${ }^{\mathrm{c}}$, Giuliano Freddi ${ }^{\mathrm{c}}$, \\ Artur Cavaco-Paulo ${ }^{\mathrm{a}, *}$ \\ a Textile Engineering Department, University of Minho, Campus of Azurém, Guimarães, Portugal \\ b CICS, Health Sciences Research Sciences, Department of Pharmaceutical Sciences, Instituto Superior de Ciências da Saúde - Norte, Rua Central de Gandra, 1317, 4585-116 Gandra-PRD, \\ Portugal \\ c Stazione Sperimentale per la Seta, via Giuseppe Colombo 83, 20133 Milan, Italy
}

\section{A R T I C L E I N F O}

\section{Article history:}

Received 8 July 2011

Received in revised form 24 February 2012

Accepted 29 February 2012

Available online 7 March 2012

\section{Keywords:}

Protein disulphide isomerase

Ribonuclease A

Ultrasound

Microspheres

Activity recovery

Protein release

Protein folding

\begin{abstract}
A B S T R A C T
The present communication describes for the first time the development of Ribonuclease A (RNase A) microspheres using the sonochemical method followed by an enzymatic treatment with protein disulphide isomerase (PDI). Ultrasound application induced changes on the protein physicochemical and biological properties: the enzymatic activity of RNase A was decreased in $35 \%$ and the free thiol groups content was significantly increased, probably due to the breakage of protein disulphide bonds and assembly of RNase A monomers. The deconvolution of amide I band, from Fourier Transform Infrared Spectroscopy, showed that the secondary structure of RNase A was slightly changed after microspherization. The PDI application on microspheres promoted the recovery of RNase A biological activity and induced the release of active protein into solution in its native state. These results were promoted by different states of PDI active site: oxidized and reduced, respectively. The PDI aptitude to catalyze the refolding of a protein substrate in the form of spheres is here reported.
\end{abstract}

(C) 2012 Elsevier B.V. All rights reserved.
Significant loss of biological activity is a major drawback inherent to the methods used in the preparation of nano and microspheres. Techniques such as phase separation, suspension cross-linking, coacervation or controlled desolvation are examples of that (Arshady, 1990; Bernstein et al., 1997; Gander et al., 2006; Lin et al., 1993; Mathiowitz et al., 1993). The ultrasonication methodology, however, has been reported to induce less damage on enzymes, decreasing the activity but not leading to denaturation (Avivi and Gedanken, 2005, 2007). Nevertheless, the recovery of the lost activity of sonochemically prepared microspheres has never been described.

In this communication, we report the application of protein disulphide isomerase (PDI) on sonochemically prepared Ribonuclease A (RNase A) microspheres in order to refold them for increased recovery of biological activity.

RNase A is a well-characterized protein of 124 amino acids and a molecular weight of $13.7 \mathrm{kDa}$ (Berisio et al., 2002) with relevance to medical practice. Various forms of this protein, including its oligomers, have been demonstrated for antitumor

\footnotetext{
* Corresponding author. Tel.: +351 253510271; fax: +351 253510293.

E-mail address: artur@det.uminho.pt (A. Cavaco-Paulo).

1 These authors contributed equally to the work.
}

and other biological activities (Fu et al., 2004; Matousek et al., 2003; Soucek et al., 1999). The development of microspheres comprising this protein is therefore of major importance for improved biological activity towards the over mentioned substrates. To date, RNase A microspheres were only prepared by miniemulsion polymerization method (Tan and Tong, 2006). Ultrasonication has the advantage of being a low-cost and high efficient one-step procedure that develop particles at high concentrations with high stability and long shelf life (Gedanken, 2008). In this study, the refolding mechanism of sonochemically prepared Ribonuclease $\mathrm{A}$ (RNase A) microspheres was assisted by PDI.

PDI is an enzyme involved in the correct folding of many proteins in vivo. It is expressed on the endoplasmic reticulum of cells and possesses three major activities: reduction, oxidation, and isomerisation of disulphide bonds in protein substrates. The PDI's active site contains two cysteines that can either form an intramolecular disulphide (oxidized PDI) which mediates the oxidase activity, or exist in the dithiol form (reduced PDI) which mediates the isomerase or reductase activity (Freedman, 1995; Gilbert et al., 1991; Lyles and Gilbert, 1991; Wilkinson and Gilbert, 2004). PDI is thought to induce the state of lower energy on non-native RNase A substrates, such as microspheres, promoting therefore the proper refolding that leads to the native state (Anfinsen, 1973). 

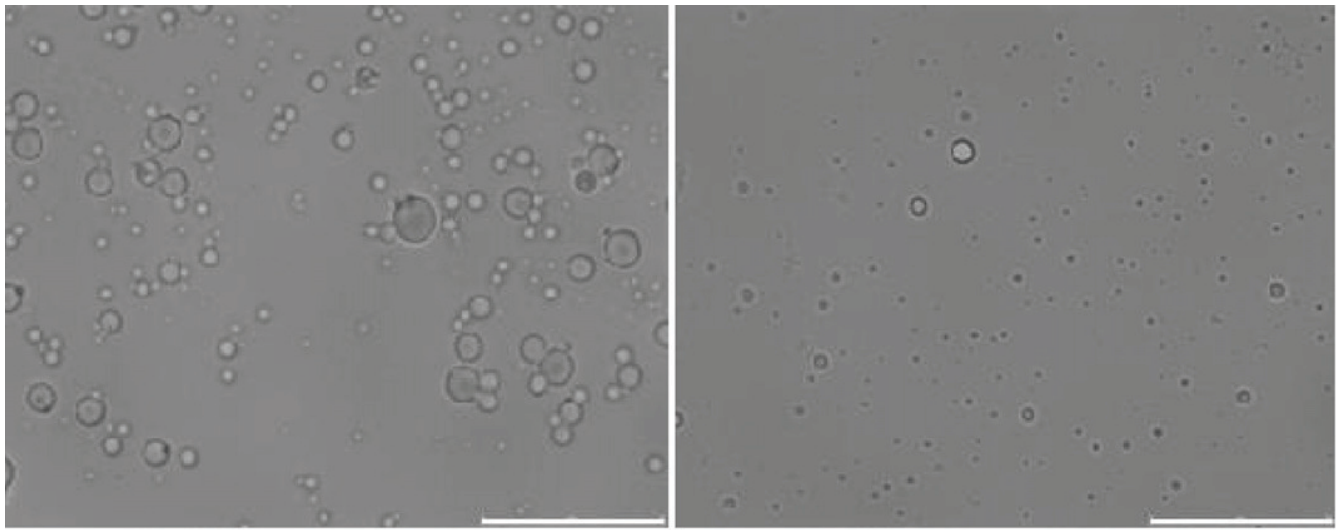

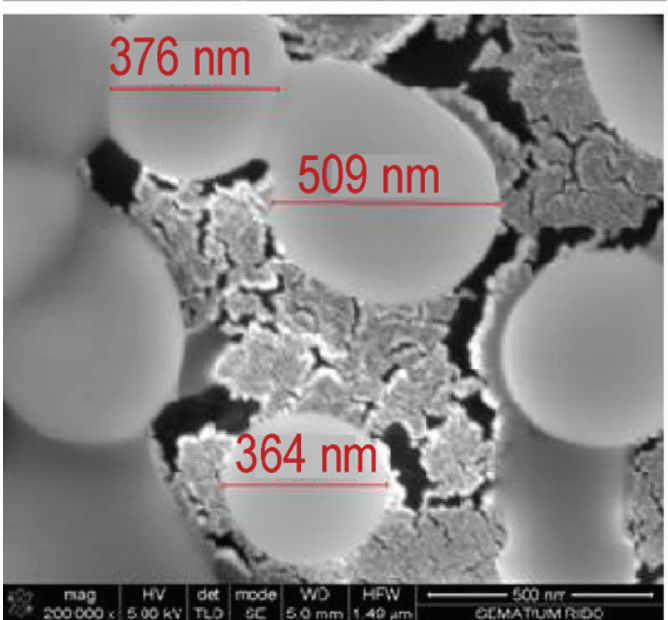

A

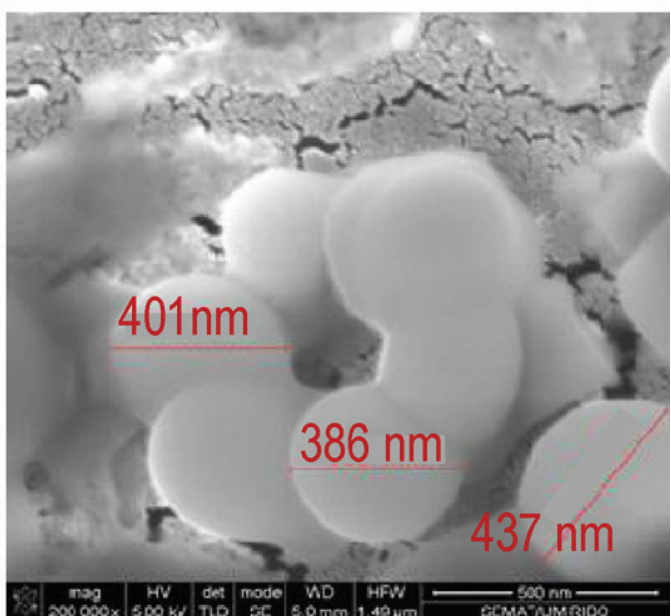

B

Fig. 1. Light microscope images (upper panel) at a magnification of $100 \times$; bar indicates $25 \mu \mathrm{m}$ and scanning electron microscopy (SEM) images (lower panel) of proteinaceous RNase A microspheres: (A) particles emulsion and (B) freeze dried particles.

In order to accomplish the established goal, the work was divided in two main parts: (i) characterization of RNase A microspheres and (ii) PDI-assisted refolding of RNase A microspheres by manipulation of enzyme active site.

\section{RNase A microspheres characterization}

Solvent-filled RNase A microspheres were developed by the method first reported by Suslick and Grinstaff (1990) and recently used by Gedanken (2008). The application of high intensity ultrasound as a method for the synthesis of RNase A microspheres resulted in $84 \%$ of particles formation efficiency and developed spherical particles (Fig. 1) with average sizes of $400 \mathrm{~nm}$ and negative charge $(-20 \pm 3 \mathrm{mV}$ ) (Table 1$)$. More thiol groups were observed on protein microspheres rather than in native protein, measured by Ellman's method (Ellman, 1959). The increased content of protein thiol groups at the surface of the particle suggested that disulphide bonds might have been disrupted upon ultrasound

Table 1

Particles characterization and conformational assessment of native and RNase A microspheres.

\begin{tabular}{|c|c|c|c|}
\hline & & \multicolumn{2}{|l|}{ RNase A } \\
\hline & & $\begin{array}{l}\text { Before microspherization } \\
\text { native protein }\end{array}$ & $\begin{array}{l}\text { After microspherization } \\
\text { particle }\end{array}$ \\
\hline \multirow[t]{4}{*}{ Particles Characterization } & $\mathrm{SH}$ (free thiol groups) & $1.9 \pm 0.8$ & $32 \pm 3$ \\
\hline & Activity (U/mg) & $5.49 \pm 0.04$ & $3.56 \pm 0.02$ \\
\hline & Size & $44 \pm 2 \mathrm{~nm}^{\mathrm{a}}$ & $412 \pm 54 \mathrm{~nm}$ \\
\hline & Zeta potential $(\mathrm{mV})$ & n.d. & $-20 \pm 3$ \\
\hline \multirow{4}{*}{ Conformational assessment } & $\beta$-sheets (\%) & 39 & 42 \\
\hline & $\alpha$-helix (\%) & 26 & 20 \\
\hline & $\beta$-turns (\%) & 22 & 16 \\
\hline & Random coil (\%) & 13 & 22 \\
\hline
\end{tabular}

a Size corresponding to the biggest dimension of native RNase A (PDB code 1FS3) (Chatani, E., Hayashi, R., Moriyama, H., Ueki, T., 2002. Conformational strictness required for maximum activity and stability of bovine pancreatic ribonuclease A as revealed by crystallographic study of three Phe120 mutants at $1.4 \AA$ resolution. Protein Sci. 11,1 , 72-81). 
application (Table 1) and/or that several RNase A monomers assemble together to form the microsphere ( $\sim 16$, assuming that each protein monomer possess 2 free thiol groups). Both theories imply that protein structural conformation might have been dramatically changed after ultrasound application. To study this, Fourier Transform Infrared (FTIR) spectra were acquired for native RNase A protein and microspheres, and the differences between them were compared after amide I band deconvolution (Byler and Susi, 1986; Kong et al., 2005) (see Supplementary data). A quantitative analysis of their secondary structure in water is given in Table 1. The native protein contained major $\beta$-sheet 39\%, followed by $\alpha$ helix $26 \%$, turns $22 \%$ and random coil structure $13 \%$. These results are consistent with other FTIR spectroscopic and X-ray crystallographic studies made on native RNase A protein, which indicated $38 \%$ of $\beta$-sheet; $20-28 \%$ of $\alpha$-helix; $20 \%$ of turns and $16 \%$ of random coil when analysis were performed with FTIR methodology and $46 \%$ of $\beta$-sheet; $22-23 \%$ of $\alpha$-helix; $21 \%$ of turns and $10 \%$ of random coil when analysis were performed with X-ray crystallography (Goormaghtigh et al., 1990; Levitt and Greer, 1977; Seshadri et al., 1994).

After microspheres development, some differences were observed; the $\beta$-sheet structure was increased from $39 \%$ to $42 \%$, whereas the $\alpha$-helix decreased from $26 \%$ to $20 \%$. Despite these changes, the secondary structure was essentially maintained indicating that ultrasound did not induce dramatic structural changes. The observed small spectral alterations were thought to be a consequence of both thiol reduction and/or aggregation of RNase A monomers that form the microsphere, as suggested above.

The biological properties of RNase A microspheres were also determined. In form of microspheres the protein lost nearly 35\% of its activity (Table 1) when compared to native protein. Partial unfolding, disulphide reduction, disulphide scrambling or protein oxidation by free radicals, are factors that may have contributed to this protein activity loss. Also, the active sites of the RNase A microspheres might have been buried after ultrasound application inhibiting the protein activity (Avivi and Gedanken, 2007).

\section{PDI application on microspheres}

Considering that ultrasound only disrupt some of the disulphide bonds in the RNase A protein, it is expected that an enzyme active towards thiol groups and disulphide bonds, such as PDI, is able to recover the activity lost during sonication. This is due to its ability to act upon disulphide bonds in a wide range of substrates, as previously proved by our group (Fernandes et al., 2011).

The enzymatic application of PDI on RNase A microspheres was then performed based on the ability of PDI to promote the oxidative folding of RNase A (Lyles and Gilbert, 1991). The PDI capacity to refold the RNase A microspheres by the oxidation of thiol groups or by isomerisation of non-native disulphide bonds, in appropriate redox conditions, was studied. Equilibrium concentrations of oxidized and reduced glutathione, $[\mathrm{GSH}]=0.1 \mathrm{mM}$ and $[G S S G]=1.0 \mathrm{mM}$, were applied together with PDI $(8 \mu \mathrm{M})$ on microspheres. These conditions promoted a redox environment with a potential of $\Delta E=-180 \mathrm{mV}$, which is reported as the optimal condition for the PDI oxidase activity (Lundström and Holmgren, 1993).

Fig. 2 shows the variation of biological activity of RNase microspheres with time in the presence of three different environments: PDI $(8 \mu \mathrm{M})$ and GSH/GSSG $\Delta E=-180 \mathrm{mV}$, the control redox buffer GSH/GSSG $\Delta E=-180 \mathrm{mV}$, and the control $(0.1 \mathrm{M} \mathrm{PB}(\mathrm{pH} 7.5)$ ). The activity of microspheres was recovered at the same yield in both catalyzed and non-catalyzed refolding reaction. It is believed that the application a redox potential of $-180 \mathrm{mV}$, either with or

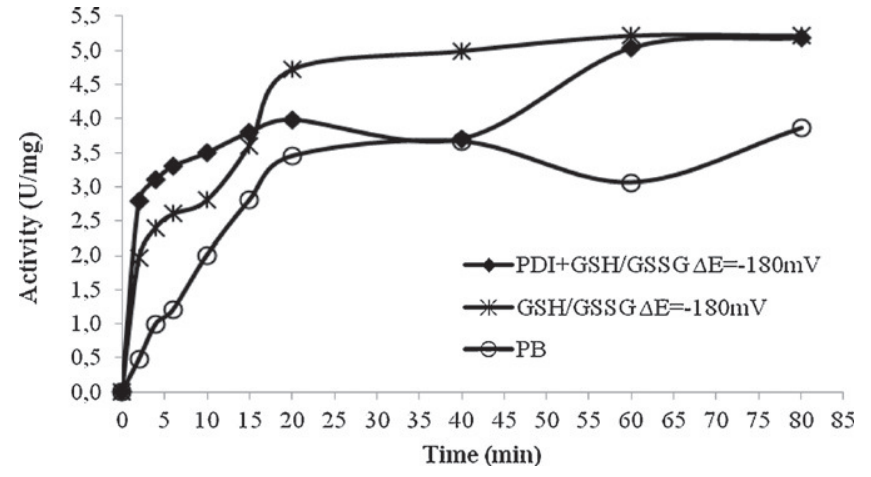

Fig. 2. Time-course reaction of the oxidative folding of RNase A lyophilized microspheres in the presence of (1) PDI + GSSG/GSH $\Delta E=-180 \mathrm{mV}$ buffer, (2) GSH/GSSG $\Delta E=-180 \mathrm{mV}$ buffer and (3) $0.1 \mathrm{M} \mathrm{PB}$ control.

without PDI, promoted the oxidation of free thiol groups rather than its reduction, that in this case would eventually cause the release of RNase A monomers. The presence of PDI increased the activity of microspheres to $5.18 \mathrm{U} / \mathrm{mg}$, in approximately the same extent of the redox buffer (5.22 $\mathrm{U} / \mathrm{mg}$; Table 2 ). When compared with the native protein activity (5.49 $\mathrm{U} / \mathrm{mg}$; Table 1 ) it could be concluded that both conditions were able to fully recover the microspheres activity. However, the activity recovery of RNase A microspheres was higher when PDI was present (Table 2). It is thought that PDI provides a faster and alternative pathway for microspheres refolding, thus demonstrating the catalytic ability of PDI to act on RNase A microspheres. In fact, the role of the redox buffers in protein folding is believed to be important in the formation of folding intermediates by increasing the rate of thiol-disulphide interchange reactions involved in protein folding (Gough and Lees, 2005; Ono et al., 2005) which may explain the maximum of biological activity. On the other hand, these results corroborate the findings that the structural conformation of microspheres does not undergo major changes otherwise the same behavior on catalyzed and non-catalyzed reaction should not be observed.

An interesting result came along when the PDI-assisted refolding of microspheres was tested in the presence of stronger reductive power. The refolding tests were performed in the presence of two redox buffers: GSH/GSSG $(1.0 \mathrm{mM} / 0.2 \mathrm{mM})$ $\Delta E=-260 \mathrm{mV}$ and DTT $(100 \mathrm{mM}) \Delta E=-360 \mathrm{mV}$. These redox buffers were applied on microspheres to create the appropriate redox environment for the reduction of PDI active site accordingly to Eqs. (1) and (2).

$\mathrm{PDI}_{\mathrm{Ox}}+\mathrm{GSH} \rightleftarrows \mathrm{PDI}_{\mathrm{red}}+\mathrm{GSSG}$

$\mathrm{PDI}_{\mathrm{ox}}+\mathrm{DTT}_{\mathrm{red}} \rightleftarrows \mathrm{PDI}_{\mathrm{red}}+\mathrm{DTT}_{\mathrm{ox}}$

The conditions applied in Eq. (1) have been reported as optimum for promoting the renaturation of RNase A through the isomerisation of non-native disulphide bonds, by the application of a redox potential of $\Delta E=-260 \mathrm{mV}$. The refolding activity of microspheres was controlled by the quantification of active RNase A that was

Table 2

Initial velocities of RNase A microspheres activity recovery after $80 \mathrm{~min}$, in the presence and absence of protein disulphide isomerase (PDI).

\begin{tabular}{lcc}
\hline Conditions & $V_{0}(\mu \mathrm{M} / \mathrm{min})$ & $\begin{array}{l}\text { Final activity } \\
(\mathrm{U} / \mathrm{mg})\end{array}$ \\
\hline PDI + GSH/GSSG $\Delta E=-180 \mathrm{mV}$ & $0.20 \pm 0.04$ & $5.18 \pm 0.03$ \\
GSSG/GSH $\Delta E=-180 \mathrm{mV}$ & $0.16 \pm 0.09$ & $5.22 \pm 0.02$ \\
PB control & $0.13 \pm 0.03$ & $3.86 \pm 0.02$ \\
\hline
\end{tabular}




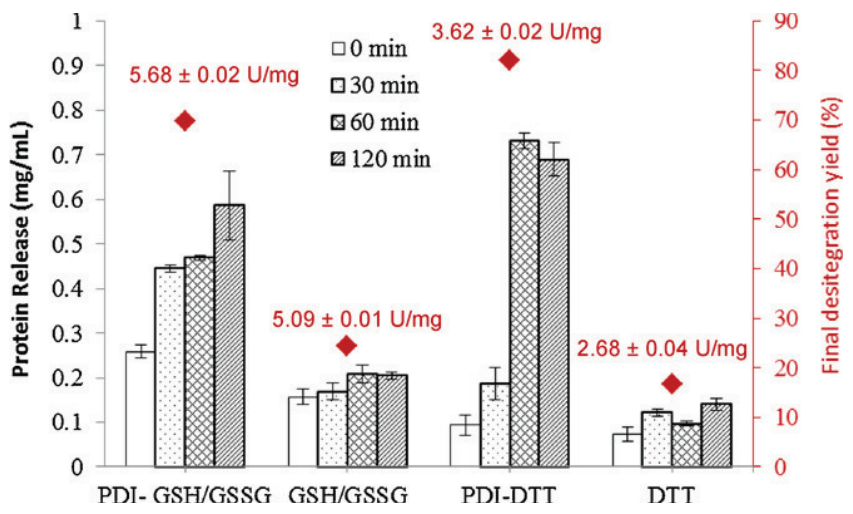

Fig. 3. RNase A release from microspheres emulsion, RNase A microspheres disintegration yield and final activity on aqueous phase after treatment with: (1) PDI with GSH/GSSG $\Delta E=-260 \mathrm{mV}$ buffer, (2) GSSG/GSH $\Delta E=-260 \mathrm{mV}$ buffer, (3) PDI with DTT $\Delta E=-360 \mathrm{mV}$ and (4) DTT $\Delta E=-360 \mathrm{mV}$, and final protein activity.

released to the aqueous medium after addition of PDI. A tendency of increasing the protein content on aqueous phase was shown when PDI was applied in the presence of either redox buffers. Moreover, a higher degree of microspheres disintegration was also observed when PDI was present (Fig. 3), suggesting a pronounced release of RNase A monomers. The absence of PDI however, did not promote an increase on protein content, expressing the failure of redox buffers alone in promoting refolding in this case.

The PDI-refolding mechanism in the presence of DTT redox buffer seems to induce more protein release, probably due to the most reducing environment promoted by this buffer. It is thought, however, that PDI and its reducing environment might promote other mechanism rather than refolding, such as misfolding (disulphide scrambling) or chemical unfolding of microspheres, explaining as well the protein release. Final activity measurements show that, in fact, the protein was released in its active form (at maximum biological activity) when PDI was applied with $\mathrm{GSH} / \mathrm{GSSG} \Delta E=-260 \mathrm{mV}$ buffer and in non-native form (at low biological activity) when PDI was applied with DTT $\Delta E=-360 \mathrm{mV}$ (Fig. 3).

These results indicate that PDI promotes the protein release into aqueous medium through two different mechanisms: by refolding when GSH/GSSG $\Delta E=-260 \mathrm{mV}$ redox buffer is used; or by misfolding/chemical unfolding when DTT $\Delta E=-360 \mathrm{mV}$ is present.

The development of redox-sensitive, disulphide-based carrier systems is an important approach when considering the redox-potential gradient of the extra- and intracellular redox environment on cells. Outside cells, disulphide bonds provide high stability to the delivery system, but are rapidly cleaved inside cells, facilitating the release of therapeutic molecules (Bauhuber et al., 2009). In fact, the composition of the redox buffer used in this study mimics the redox environment on healthy cells, where PDI is naturally present in a reducing environment with a GSH/GSSG ratio of 5 (Hwang et al., 1992). This fact indicates the possibility of using RNase A microspheres for model drugs or RNase A delivery purposes.

\section{Conflict of interest}

The authors have declared no conflict of interest.

\section{Acknowledgment}

Margarida Fernandes thanks FCT "Fundação para a Ciência e Tecnologia" for providing the grant for $\mathrm{PhD}$ studies
(SFRH/BD/38363/2007). Helena Ferreira thanks POPH/FSE for cofinancing and FCT for fellowship SFRH/BPD/38939/2007.

\section{Appendix A. Supplementary data}

Supplementary data associated with this article can be found, in the online version, at doi:10.1016/j.jbiotec.2012.02.016.

\section{References}

Anfinsen, C.B., 1973. Principles that govern the folding of protein chains. Science 181 (4096), 223-230.

Arshady, R., 1990. Albumin microspheres and microcapsules: methodology of manufacturing techniques. J Control. Release 14 (2), 111-131.

Avivi, S., Gedanken, A., 2005. The preparation of avidin microspheres using the sonochemical method and the interaction of the microspheres with biotin. Ultrason. Sonochem. 12 (5), 405-409.

Avivi, S., Gedanken, A., 2007. Are sonochemically prepared [alpha]-amylase protein microspheres biologically active? Ultrason. Sonochem. 14, 1-5.

Bauhuber, S., Hozsa, C., Breunig, M., Göpferich, A., 2009. Delivery of nucleic acids via disulfide-based carrier systems. Adv. Mater. 21 (32-33), 3286-3306.

Berisio, R., Sica, F., Lamzin, V.S., Wilson, K.S., Zagari, A., Mazzarella, L., 2002. Atomic resolution structures of ribonuclease A at six pH values. Acta Crystallogr. D 58 (3), 441-450.

Bernstein, H., Morrel, E., Mathiowitz, E., Schwaller, K., Beck, T.R., 1997. Protein microspheres and methods of using them, United States patent.

Byler, D.M., Susi, H., 1986. Examination of the secondary structure of proteins by deconvolved FTIR spectra. Biopolymers 25 (3), 469-487.

Ellman, G.L., 1959. Tissue sulfhydryl groups. Arch. Biochem. Biophys. 82 (1), $70-77$.

Fernandes, M.M., Gomes, A., Vasconcelos, A., Munteanu, F.-D., Tzanov, T., Gonçalves, M., End, N., Schoening, K.-U., Guebitz, G., Cavaco-Paulo, A., 2011. Protein disulphide isomerase-assisted functionalization of keratin-based matrices. Appl. Microbiol. Biotechnol. 90 (4), 1311-1321.

Freedman, R.B., 1995. The formation of protein disulphide bonds. Curr. Opin. Struct. Biol. 5 (1), 85-91.

Fu, P., Chen, J., Tian, Y., Watkins, T., Cui, X., Zhao, B., 2004. Anti-tumor effect of hematopoietic cells carrying the gene of ribonuclease inhibitor. Cancer Gene Ther. 12 (3), 268-275.

Gander, B., Blanco-PrÃ-eto, M.J., Thomasin, C., Wandrey, C., Hunkeler, D., 2006. Coacervation and Phase Separation. Encyclopedia of Pharmaceutical Technology, 3rd ed, pp. 600-614.

Gedanken, A., 2008. Preparation and properties of proteinaceous microspheres made sonochemically. Chem. Eur. J. 14 (13), 3840-3853.

Gilbert, H.F., Kruzel, M.L., Lyles, M.M., Harper, J.W., 1991. Expression and purification of recombinant rat protein disulfide isomerase from Escherichia coli. Protein Expr. Purif. 2 (2-3), 194-198.

Goormaghtigh, E., Cabiaux, V., Ruysschaert, J.-M., 1990. Secondary structure and dosage of soluble and membrane proteins by attenuated total reflection Fouriertransform infrared spectroscopy on hydrated films. Eur. J. Biochem. 193 (2), 409-420.

Gough, J.D., Lees, W.J., 2005. Effects of redox buffer properties on the folding of a disulfide-containing protein: dependence upon $\mathrm{pH}$, thiol $\mathrm{p} K_{\mathrm{a}}$, and thiol concentration. J. Biotechnol. 115 (3), 279-290.

Hwang, C., Sinskey, A., Lodish, H., 1992. Oxidized redox state of glutathione in the endoplasmic reticulum. Science 257 (5076), 1496-1502.

Kong, H., Ye, F., Lu, X., Guo, L., Tian, J., Xu, G., 2005. Deconvolution of overlapped peaks based on the exponentially modified Gaussian model in comprehensive two-dimensional gas chromatography. J. Chromatogr. A. 1086 (1-2), $160-164$.

Levitt, M., Greer, J., 1977. Automatic identification of secondary structure in globular proteins. J. Mol. Biol. 114 (2), 181-239.

Lin, W., Coombes, A., Davies, M., Davis, S., Illum, L., 1993. Preparation of sub-100 nm human serum albumin nanospheres using a pH-coacervation method. J. Drug Target. 1 (3), 237-243.

Lundström, J., Holmgren, A., 1993. Determination of the reduction-oxidation potential of the thioredoxin-like domains of protein disulfide-isomerase from the equilibrium with glutathione and thioredoxin. Biochemistry 32 (26), 6649-6655.

Lyles, M.M., Gilbert, H.F., 1991. Catalysis of the oxidative folding of ribonuclease A by protein disulfide isomerase: dependence of the rate on the composition of the redox buffer. Biochemistry (US) 30 (3), 613-619.

Mathiowitz, E., Bernstein, H., Morrel, E., Schwaller, K., 1993. Method for Producing Protein Microspheres, United States.

Matousek, J., Gotte, G., Pouckova, P., Soucek, J., Slavik, T., Vottariello, F., Libonati, M., 2003. Antitumor activity and other biological actions of oligomers of ribonuclease A. J. Biol. Chem. 278 (26), 23817-23822.

Ono, T., Nagatomo, M., Nagao, T., Ijima, H., Kawakami, K., 2005. Nonaggregating refolding of ribonuclease A using reverse micellar dialysis. Biotechnol. Bioeng. 89 (3), 290-295.

Seshadri, S., Oberg, K.A., Fink, A.L., 1994. Thermally denatured ribonuclease A retains secondary structure as shown by FTIR. Biochemistry 33 (6), 1351-1355. 
Soucek, J., Raines, R.T., Haugg, M., Raillard-Yoon, S.-A., Benner, S.A., 1999. Structural changes to ribonuclease A and their effects on biological activity. Comp. Biochem. Physiol. C 123 (2), 103-111.

Suslick, K.S., Grinstaff, M.W., 1990. Protein microencapsulation of nonaqueous liquids. J. Am. Chem. Soc. 112 (21), 7807-7809.
Tan, C.J., Tong, Y.W., 2006. Preparation of superparamagnetic ribonuclease A surfaceimprinted submicrometer particles for protein recognition in aqueous media. Anal. Chem. 79 (1), 299-306.

Wilkinson, B., Gilbert, H.F., 2004. Protein disulfide isomerase. Biochim. Biophys. Acta $1-2,35-44$. 